\title{
High Temperature Deformation and Dynamic Recrystallization Behavior of Alloy718
}

\author{
Takanori Matsui* \\ MMC Superalloy Corporation, Kitamoto 364-0023, Japan
}

\begin{abstract}
Ni base superalloy is one of the representative heat resistant materials for high temperature environment in various industrial applications. As for cast and wrought material, thermo-mechanical processing during hot forging has a significant role to control and optimize crystal grain structure in order to attain required critical properties. The essential deformation and dynamic recystallization behavior of Ni base superalloy, Alloy718 during hot forging were revealed through hot compression tests and quantitative relations among various parameters that were available for numerical calculation were derived. Dynamically recrystallized grain diameter depended on temperature, strain rate and was independent of initial grain diameter and strain. And the grain diameter was expressed as a function of the temperature compensated strain rate, i.e., Zener-Hollomon parameter quantitatively. Avrami-type equation was available for comprehensive and quantitative expression of dynamic recrystallization transition tendency. And the fraction of dynamic recrystallization was a function of the given strain and the strain for $50 \%$ recrystallization which depended on the initial grain diameter and Zener-Hollomon parameter. [doi:10.2320/matertrans.M2012202]
\end{abstract}

(Received June 1, 2012; Accepted January 29, 2013; Published March 25, 2013)

Keywords: superalloy, alloy718, isothermal compression, hot deformation, peak stress, Zener-Hollomon parameter, dynamic recrystallization, dynamically recrystallized grain diameter, fraction of dynamic recrystallization, numerical calculation

\section{Introduction}

$\mathrm{Ni}$ base superalloy is one of the representative heat resistant materials for high temperature environment in various industrial applications, especially in aero-engine. The alloy is applied to hot section parts as core material having a great inference on the performance of jet engine and is exposed to extreme severe condition comprising elevated temperature and considerable stress. Many kinds of alloy and regarding process has been proposed and applied up to the present.

Alloy718 developed in the late 1950s is one of the most famous and widely used Ni base superalloy in the world. ${ }^{1-4)}$ The alloy is categorized as $\gamma-\gamma^{\prime \prime}$ type superalloy based on its major strength mechanism and has excellent mechanical properties in the temperature range below $923 \mathrm{~K}$ compared to $\gamma-\gamma$ type Ni base superalloys due to extreme fine and coherent precipitation of $\gamma^{\prime \prime}$ phase. And appropriate properties regarding manufacture and repair such as formability, weldability, and chemical composition having relative high content of economical Fe without expensive Co are attractive features for practical use. In cast and wrought material application, it is also noteworthy that there are several kinds of derivative alloy characterized by not only chemical composition and cleanness but also structure of crystal grain and precipitation brought by thermo-mechanical processing. Such derivatives called high strengthened, direct aged are utilized as critical and important material in aero engine. Thermo-mechanical processing during hot forging has particularly a significant role to control and optimize crystal grain structure in order to attain required critical properties in Alloy718. It means that the control of dynamic recrystallization behavior is the matter of importance. Dynamic recrystallization brings equiaxed grain structure that is independent of stressed direction and makes uniform

*Corresponding author, E-mail: matsui@mmc.co.jp and fine grain distribution under specific condition. Moreover occurrence of dynamic recrystallization reduces deformation stress and suppress cracking tendency on grain boundary. Utilization of dynamic recrystallization behavior is attractive from the view point of both property and plastic deformation control. Therefore precise understanding of dynamic recrystallization behavior under hot deformation is important so as to obtain equiaxed and homogenous grain distribution relating to required mechanical properties and reliabilities in various hot section parts.

Moreover specified shape should be achieved in forging stage. Such requirement that appropriate shape and metallurgical structure are given at the same time causes comprehensive history of various parameters such as temperature, strain rate and strain in whole forging.

Numerical simulation is thought to be useful for understanding of thermo-mechanical history as integration of momentary phenomenon and for optimization of operation procedure. ${ }^{5-8)}$ The technology has widely been utilized to understand complicated phenomena and solve tangled problems in various fields under remarkable development of hardware. Numerical calculation is also available for prediction and verification of the microstructure transformation during hot deformation. Because it is hard to observe actually whole microstructure evolution brought by sequential transition of thermal and mechanical condition and is also difficult to estimate such change on the basis of knowledge and experience. For utilization of modeling, all the relationship regarding microstructure should be expressed as quantitative equations.

Industrial critical forging parts brought by cast and wrought process for elevated temperature application in aero engine generally requires homogenous equiaxed grain structure having specified average grain size in order to gain isotropic aimed mechanical properties. Under huge amount of plastic deformation, equiaxed grain structure is never given without continuous dynamic recrystallization progress and 
Table 1 Chemical composition of evaluated material.

\begin{tabular}{|c|c|c|c|c|c|c|c|c|c|c|c|}
\hline & & $\mathrm{Fe}$ & $\mathrm{Ni}$ & $\mathrm{Cr}$ & $\mathrm{Nb}$ & Mo & $\mathrm{Al}$ & $\mathrm{Ti}$ & B & $\mathrm{C}$ & Remarks \\
\hline \multirow[t]{2}{*}{ Alloy 718} & [1] & 17.4 & 54.0 & 17.9 & 5.4 & 3.0 & 0.5 & 0.9 & 0.003 & 0.03 & $\mathrm{VIM}+\mathrm{ESR}+\mathrm{VAR}$ \\
\hline & {$[2]$} & 17.3 & 54.2 & 18.0 & 5.4 & 3.0 & 0.5 & 1.0 & 0.004 & 0.02 & $\mathrm{VIM}+\mathrm{ESR}+\mathrm{VAR}$ \\
\hline
\end{tabular}

resultant high fraction of dynamic recrystallization. Average grain size is settled by initial and recrystallized grain diameter which are coupled by recystallization ratio. It means the importance of quantitative equations regarding dynamically recrystallized grain diameter and recrystallization ratio. Moreover a series of such equations should have specific feature to be described as incremental form when it's applied for numerical calculation.

The objective in this study is to reveal the essential deformation and dynamic recystallization behavior of $\mathrm{Ni}$ base superalloy, Alloy718 during hot forging through various kinds of hot compression tests and to derive quantitative relationship among various parameters that is available for numerical calculation.

\section{Experimental Procedure}

\subsection{Materials}

All of tested materials in this study were the forging billet produced from triple melted ingot (vacuum induction melting followed by electoro-slag remelting and vacuum arc remelting). Chemical composition of tested material is shown in Table 1.

\subsection{Isothermal compression test}

Strain rate controlled isothermal compression tests were carried out using THERMECMASTER-Z made by Fuji Electric Industrial Co., Ltd. and having maximum load capability of $98 \mathrm{kN}$ under electrical-hydraulic control to understand the essential relationship among temperature, strain rate, strain and microstructure evolution i.e., dynamically recrystallized grain diameter, fraction of dynamic recrystallization. The specimens with $12 \mathrm{~s}$ roughness condition of surface had cylindrical shape with $8 \mathrm{~mm}$ in diameter and $12 \mathrm{~mm}$ in height. These specimens were heated up to test temperature with heating rate of $10 \mathrm{~K} / \mathrm{s}$ by induction heating and compressed after $100 \mathrm{~s}$ hold at the temperature. Test temperature was controlled and monitored with thermocouple that attached to surface in mid-height region. Each range of temperature, strain rate and total strain is 1223 $1323 \mathrm{~K}, 0.01-0.2 \mathrm{~s}^{-1}$ and $10-60 \%$ respectively. The specimens were cooled by He gas immediately to achieve quench condition.

Microstructure observation was carried out by optical microscopy for specific area with $1 / 2$ in height and $2 / 3$ in radius. The area was selected by finite element analysis as desirable observation point in which uniform conditions e.g., strain rate, temperature were achieved through compression. Grain diameter was measured in accordance with ASTM E112. The results of microstructure observation were associated to test temperature, compensated strain rate and total strain.

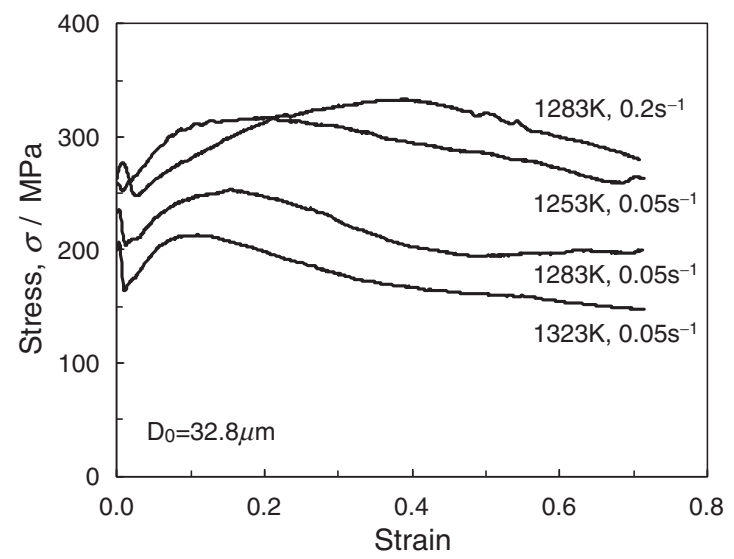

Fig. 1 Typical stress-strain curves obtained from isothermal compression tests.

\section{Results and Discussions}

\subsection{Deformation behavior}

Dynamic recrystallization behavior that occurs under stressed condition is supposed to have close relationship with deformation mechanism. The peak stress observed on stress-strain curve obtained from isothermal compression tests is analyzed in order to reveal the feature of deformation behavior when dynamic recrystallization occurs. Several representative stress-strain curves given by specimens having $32.8 \mu \mathrm{m}$ of initial grain diameter are shown in Fig. 1. The peak stress is defined as the maximum stress appeared as a result of continuous work hardening and restoration in relative low strain region. In microstructure observation, occurrence of dynamic recrystallization was confirmed in smaller strain range than peak stress and dynamic recrystallization was enhanced after passing the peak point. The fact indicates that peak stress appears as a result of drastic restoration depending on dynamic recrystallization in addition to preceding dynamic recovery. Therefore it' thought that the activation energy for deformation at peak stress and following steady stress is relevant to dynamic recrystallization behavior.

Figure 2 shows the relationship between the peak stress and three kinds of parameter, i.e., temperature, strain rate and initial grain diameter. The peak stress depends on temperature and strain rate obviously although dependence of initial grain diameter is not found. The change of peak stress across $\delta$ solvus temperature (approximately $1283 \mathrm{~K}$ ) isn't notable and the increment tendency as a function of temperature is relative small. $\delta$ phase has relative sluggish precipitation rate and precipitation hardening effect is small. These feature of $\delta$ phase corresponds to bring moderate transition tendency of peak stress across solvus temperature. 
In Fig. 3, the activation energy for deformation $Q_{\text {def }}$ and the stress exponent $n_{\text {def }}$ concerning peak stress are estimated on eq. (1) that is representative one for high temperature deformation. ${ }^{9)}$

$$
\dot{\varepsilon}=A_{\text {def }} \sigma_{\mathrm{p}}^{n_{\text {def }}} \exp \left(-Q_{\text {def }} / R T\right)
$$

where $\dot{\varepsilon}$ is the strain rate, $\sigma_{\mathrm{p}}$ is the peak stress, $n_{\text {def }}$ is the stress exponent, $Q_{\mathrm{def}}$ is the activation energy for deformation, $T$ is in absolute temperature, $R$ is the gas constant, $A_{\text {def }}$ is the material constant.

The data having three kinds of initial grain diameter is processed together according to the knowledge that initial grain diameter dependence is not found in the peak stress.

The exponent $n_{\text {def }}$ has less temperature dependence under the temperature range from 1253 to $1323 \mathrm{~K}$ and is considered as constant value of 4.7 comprehensively in spite of the temperature range across $\delta$ solvus temperature. Corresponding apparent activation energy $Q_{\text {def }}$ including the effect of non-thermally activated process is recognized as constant in evaluated temperature range. The comprehensive $Q_{\text {def }}$ is estimated as $338 \mathrm{~kJ} / \mathrm{mol}$ for $1253-1323 \mathrm{~K}$. Maki et al. derived 4.5 and 4.6 of exponent $n_{\text {def }}$ in accordance with eq. (1) from elevated temperature tensile tests for $18 \mathrm{Ni}$ maraging steel and $18-8$ stainless steel respectively. ${ }^{10)}$ Obtained exponent $n_{\text {def }}$ in this study is similar to those although they are not given from same material. In various

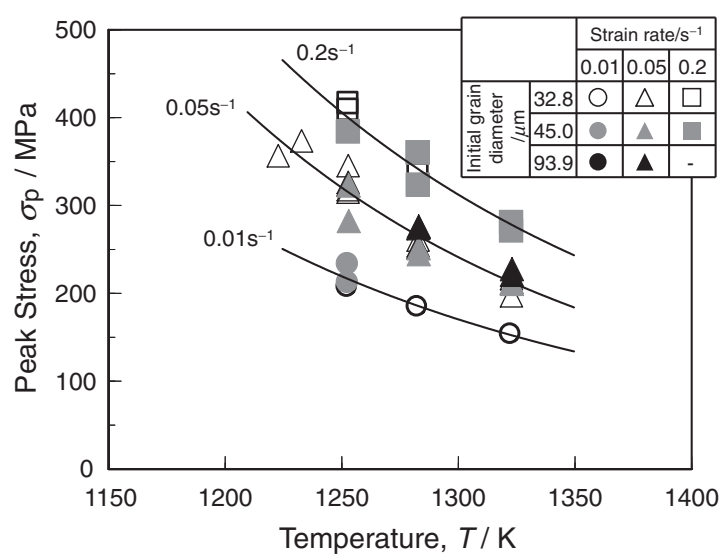

Fig. 2 Temperature, strain rate and initial grain diameter dependence of peak stress. kinds of pure metal and alloy, larger value compared to selfdiffusion energy or volume diffusion of alloying element is obtained in case that dynamic recrystallization is dominant mechanism of dynamic restoration. It's reported that the activation energy for self-diffusion of $\mathrm{Ni}$ and volume diffusion of Mo in Ni that is largest value for compositional elements are 281 and $288 \mathrm{~kJ} / \mathrm{mol}$ respectively. ${ }^{11)}$ It's confirmed that the activation energy for deformation obtained in this study is larger than the diffusion energy of compositional elements like other materials in which the deformation is dominated by dynamic recrystallization behavior.

Calculated peak stress given by eq. (1) with 4.7 of $n_{\text {def }}$ and $338 \mathrm{~kJ} / \mathrm{mol}$ of $Q_{\text {def }}$ and observed one are compared in Fig. 4 in order to verify the appropriateness of obtained $n_{\text {def }}$ and $Q_{\text {def. }}$ In Fig. 4 , the data in the range of $1223-1323 \mathrm{~K} / 0.01-$ $0.2 \mathrm{~s}^{-1}$ is analyzed and the correlation line of $\sigma_{\mathrm{p} \_ \text {cal }}=\sigma_{\mathrm{p} \_ \text {obs }}$, $\pm 10 \%$ variation range are added as desired accuracy of prediction for reference. The difference between calculation and observation is less than $\pm 10 \%$ in almost all case. It's thought to indicate the appropriateness of obtained $n_{\text {def }}$ and

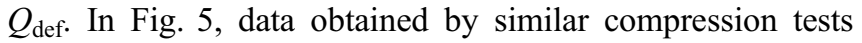
with different procedure, e.g., shape and dimension of test piece from several other reports regarding Alloy718 is evaluated in same manner with Fig. 4 for comparison. ${ }^{12-17)}$ Agreement tendency of calculated and experimental values having similar temperature and strain rate range to this study seems to depend on test condition. In lower strain rate region,

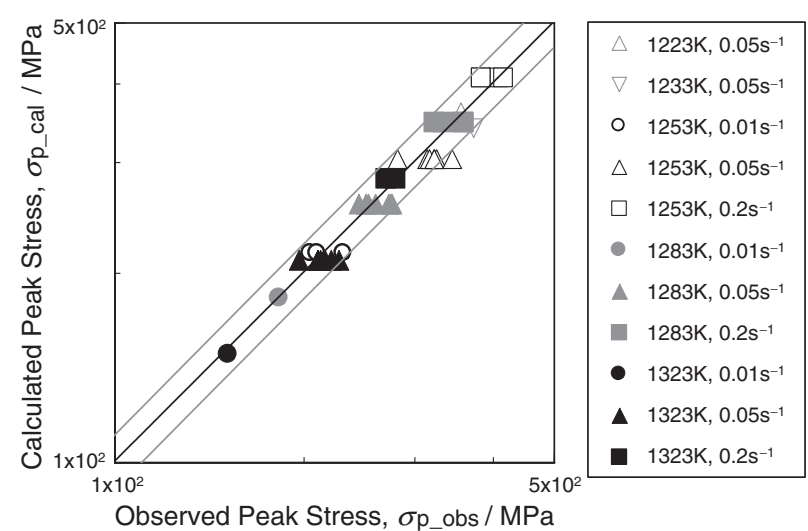

Fig. 4 Comparison of peak stress between calculation and observation.

(b)

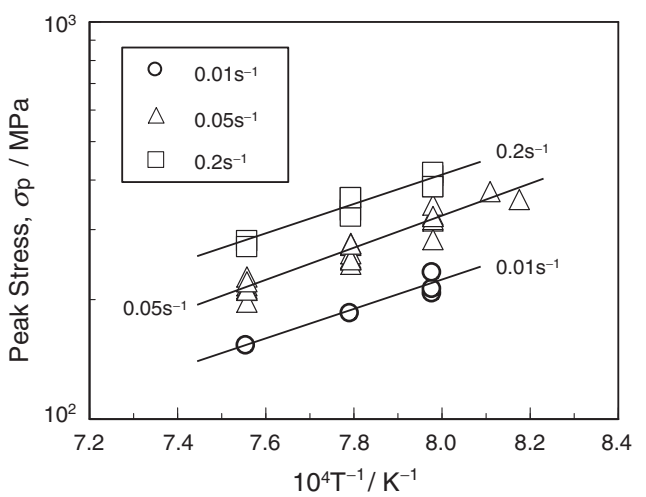

Fig. 3 The relationship between (a) strain rate and peak stress and (b) peak stress and $1 / T$. 

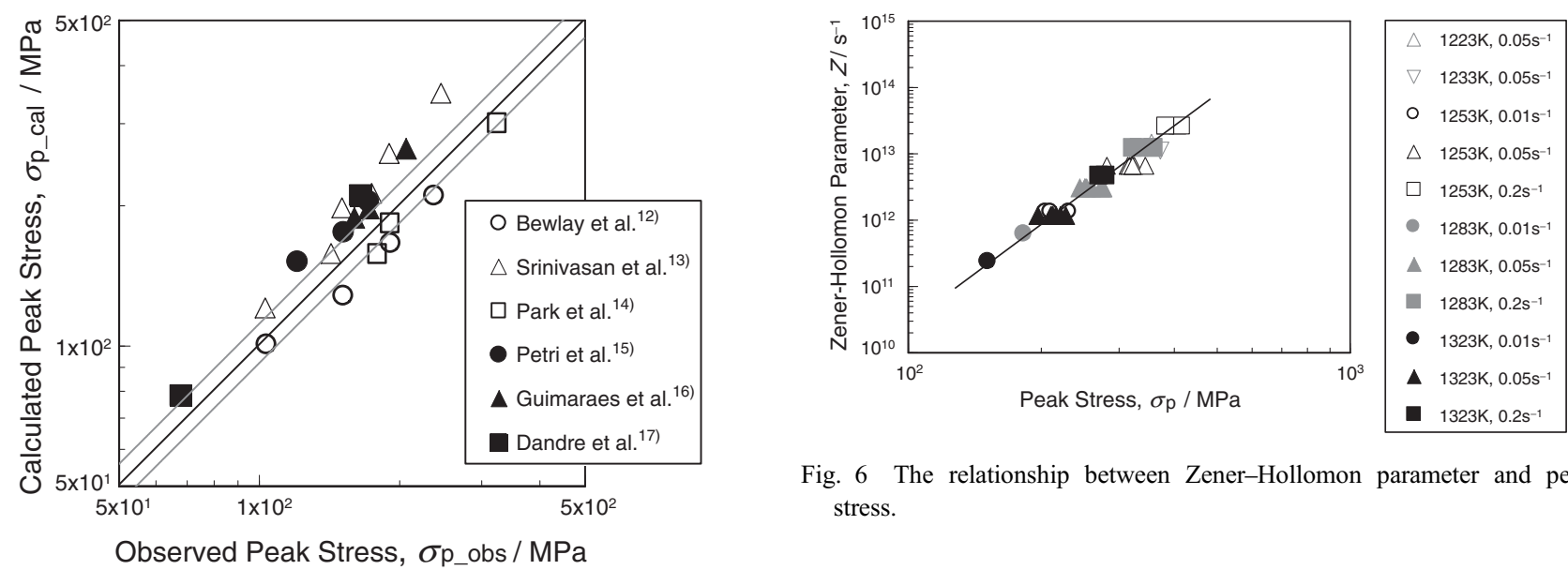

Fig. 6 The relationship between Zener-Hollomon parameter and peak stress.

Fig. 5 Comparison of peak stress between calculation and observation from other authors.

(a)

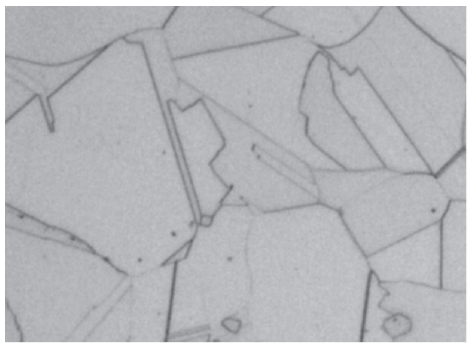

As billet

(d)

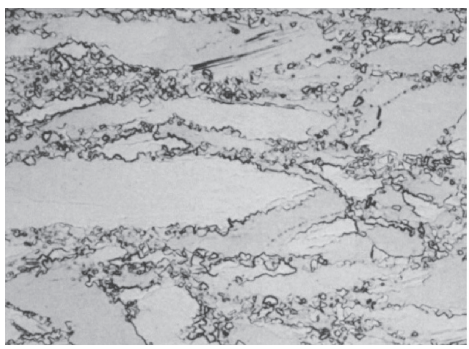

$1283 \mathrm{~K}, 0.05 \mathrm{~s}^{-1}, 60 \%$ (b)

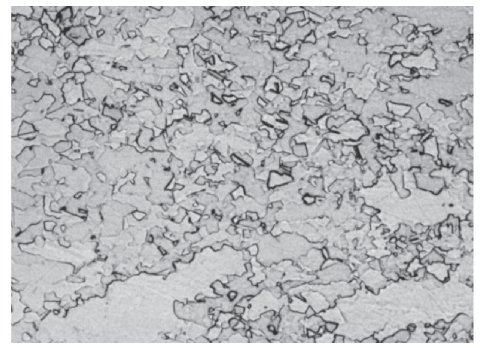

$1283 \mathrm{~K}, 0.01 \mathrm{~s}^{-1}, 60 \%$

(e)

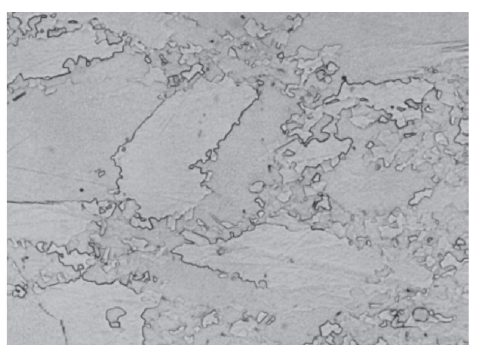

$1323 \mathrm{~K}, 0.05 \mathrm{~s}^{-1}, 40 \%$ (c)

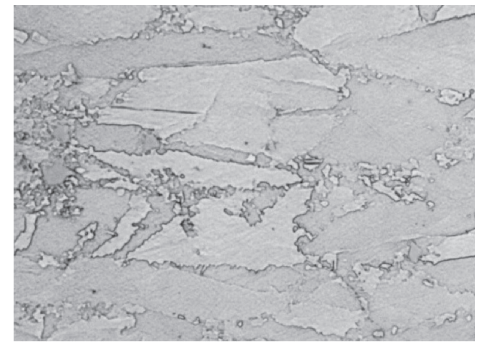

$1283 \mathrm{~K}, 0.05 \mathrm{~s}^{-1}, 40 \%$

(f)

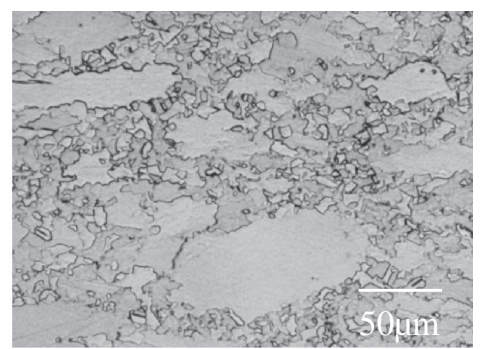

$1323 \mathrm{~K}, 0.05 \mathrm{~s}^{-1}, 60 \%$

Fig. 7 Microstructure before and after compression tests having initial grain diameter $\left(D_{0}\right)$ of $93.9 \mu \mathrm{m}$.

calculation has good agreement with observation on the whole. In higher strain rate range over approximate $0.05 \mathrm{~s}^{-1}$, overestimation tendency that prediction is higher than observation appears. The degree of difference is remarkable in lower temperature and higher strain rate. Such tendency is supposed to be caused by adiabatic heating during hot deformation and it indicates the importance of temperature control and corresponding compensation in hot deformation test for collection of precise experimental data.

Moreover the relationship between the peak stress having same temperature and strain rate region to Fig. 4 and the temperature-compensated strain rate, Zener-Hollomon parameter defined as eq. (2) is summarized in Fig. 6. ${ }^{9}$

$$
Z=\dot{\varepsilon} \exp \left(Q_{\text {def }} / R T\right)
$$

Garcia et al. investigated the deformation behavior of ascast Alloy718 through hot compression tests and reported evident relation between the peak stress and Zener-Hollomon parameter containing apparent activation energy for defor- mation. ${ }^{18)}$ Similar tendency was revealed by Weis et al. and Lewandowski et al. ${ }^{19,20)}$ Obvious correlation is confirmed in this study too and Zener-Hollomon parameter is thought to be available for quantitative expression of the peak stress.

\subsection{Dynamically recrystallized grain diameter}

One of dominant factor characterizing the microstructure revolution brought by dynamic recrystallization during hot deformation is the dynamically recrystallized grain diameter. Typical microstructures before and after compression tests are shown in Fig. 7. Dynamically recrystallized grains not depending on compression direction that is parallel to vertical of each photograph and having equiaxed structure are confirmed in any deformation condition. And the diameter of recrystallized grains has temperature and strain rate dependence. The lower the temperature is and the higher the strain rate is, the smaller the dynamically recrystallized grain diameter. Figure 8 shows the relationship between the dynamically recrystallized grain diameter and Zener- 


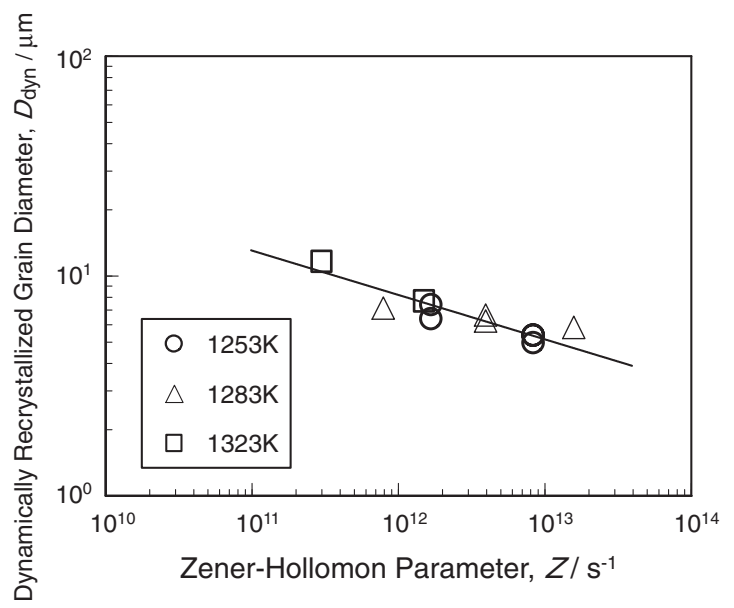

Fig. 8 The relationship between dynamically recrystallized grain diameter and Zener-Hollomon parameter.

Hollomon parameter for the temperature range from 1253 to $1323 \mathrm{~K}$. The compensated strain rate considered the difference between actual rate at microstructure observation point and apparent rate of whole test piece is applied for calculation of Zener-Hollomon parameter according to finite element analysis. It's revealed that the strain rate at observation points has approximately 1.31 times as large as nominal strain rate of compression test through calculation of compression test by finite element method. It is found that the dynamically recrystallized grain diameter has quantitative relationship with Zener-Hollomon parameter as following equation.

$$
D_{\text {dyn }}=A_{\text {dyn }} Z^{n_{\text {dyn }}}
$$

where $D_{\text {dyn }}$ is the dynamically recrystallized grain diameter, $Z$ is the Zener-Hollomon parameter, $A_{\text {dyn }}$ and $n_{\text {dyn }}$ are the material constants. The exponent $n_{\text {dyn }}$ is evaluated as -0.20 . Correlation between dynamically recrystallized grain diameter and Zener-Hollomon parameter is revealed in various materials. ${ }^{9,21,22)}$ Sakui et al. reported -3.78 as reciprocal of $n_{\text {dyn }}$, i.e., -0.28 of $n_{\text {dyn }}$ for $0.16 \% \mathrm{C}$ austenite steel. ${ }^{23)}$ Maki et al. showed -2.4 as reciprocal of $n_{\text {dyn }}$, i.e., -0.42 of $n_{\text {dyn }}$ for 18-8 stainless steel and $18 \mathrm{Ni}$ maraging steel. ${ }^{10)}$ Senuma et al. got the value of -0.27 for $\mathrm{Si}-\mathrm{Mn}$ steel and $\mathrm{Na}$ et al. reported -0.124 as exponent $n_{\text {dyn }}$ for Alloy718. ${ }^{24,25)}$ It's thought that the exponent $n_{\text {dyn }}$ in this study follows tendency given by former works although each has different temperature and strain rate region.

Moreover calculated and observed dynamically recrystallized grain diameter are compared in Fig. 9 in order to verify the convergence of estimated eq. (3). In Fig. 9, the desirable prediction range of ASTM No. \pm 1 is drawn in addition to $D_{\text {dyn_cal }}=D_{\text {dyn_obs }}$ proportional line for reference. It's confirmed that each plot exists in the range of ASTM No. \pm 1 despite consisting of obvious fine grain data under $10 \mu \mathrm{m}$. It means the validity of eq. (3) for quantitative prediction of the dynamically recrystallized grain diameter from 1253 to $1323 \mathrm{~K}$.

In addition to proper optimization for Alloy718, the possibility of comprehensive expression covering other alloys is evaluated. Comprehensive equation if given will

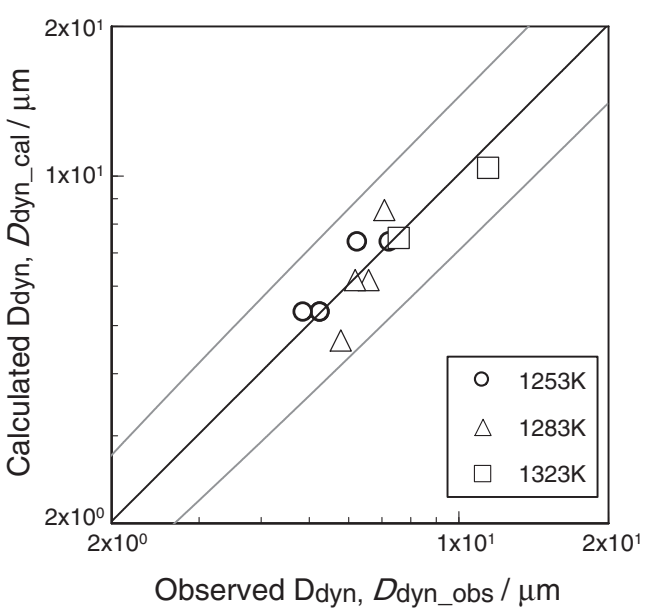

Fig. 9 Comparison of dynamically recrystallized grain diameter between calculation and observation.

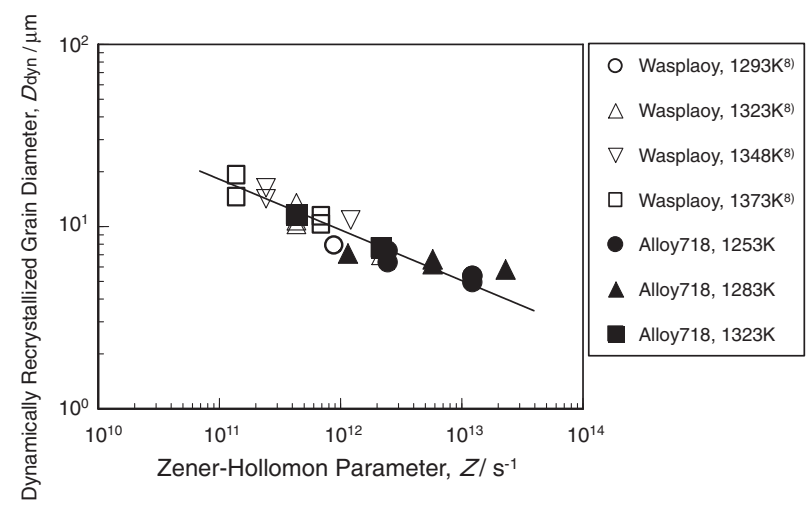

Fig. 10 The relationship between dynamically recrystallized grain diameter and Zener-Hollomon parameter for both Alloy718 and Wasplaoy.

be valuable for prediction of uncertain alloys having similar metallurgical structure and deformation mechanism but not revealed quantitative relationship between dynamically recrystallized grain diameter and various parameters. In Fig. 10, the dynamically recrystallized grain diameter of Alloy718 and Wasplaoy are summarized as a function of Zener-Hollomon parameter on basis of the fact that both alloys have microstructure consisting mainly of $\gamma$ phase and similar activation energy for hot deformation. Wasplaoy is one of representative Ni base superalloy categorized as $\gamma-\gamma^{\prime}$ type and Zener-Hollomon parameter dependence of dynamically recrystallized grain diameter was revealed in author's other study. ${ }^{8)}$ Average value of activation energy in Waspaloy and Alloy718 is applied for estimation of Zener-Hollomon parameter. It's recognized that data plot of both alloys distribute along unified correlation curve and one comprehensive equation is given. Furthermore comparison of calculation and observation in Fig. 11 shows that the practical accuracy of prediction obtained by approximate equation is attained in each alloy. The fact that single correlation is applicable for different two alloys is thought to indicate that dynamically recrystallized grain diameter is controlled by equivalent mechanism in both alloys and the equation is available for other $\mathrm{Ni}$ base alloy having equivalent microstructure evolution mechanism. 


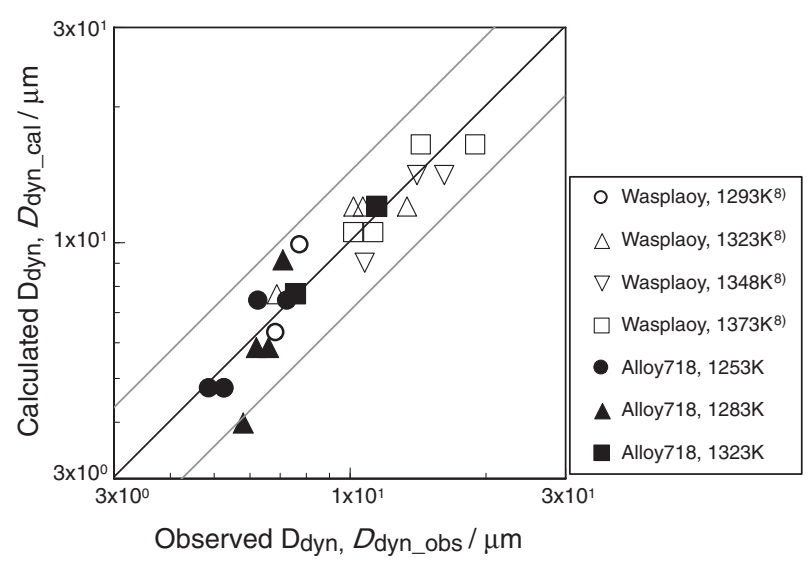

Fig. 11 Comparison of dynamically recrystallized grain diameter between calculation and observation for both Alloy718 and Wasplaoy.

\subsection{Fraction of dynamic recrystallization}

Another constituent element which characterizes dynamically recrystallized microstructure besides dynamically recrystallized grain diameter is fraction of dynamic recrystallization.

Avrami-type transition curve is one of most popular expression to follow transition tendency of solid-solid reaction as a function of time and is also utilized as formularization of static recrystallization such that transition rate of recystallization depends on unrecrystallized area and time. ${ }^{26)}$ It is thought that transition rate of dynamic recrystallization ratio has also strong relationship with unrecrystallized area. Therefore quantitative description of dynamic recrystallization ratio with Avrami-type transition curve based on Johnson-Mehl-Avrami-Kolmogorov (JMAK) theory is examined in this study. In applying Avrami-type equation, the difference of both static and dynamic recrystallizations should be understood. In case of static recrystallization, time, temperature and strain are major factor controlling transition behavior. Temperature is constant and stored strain decreases monotonously with the passage of time in almost of cases. On the other hand, concerning to dynamic recrystallization, stored strain that is changed by sequential work hardening and dynamic restoration is dominant factor to control recrystallization. Therefore strain shall be adopted as major parameter for description of transition tendency instead of time.

Important issue that should be considered for application of Avrami-type transition curve is how characterized its curve is. When Avrami-type curve is recognized as geometric figure, $\varepsilon_{0.5}$, the strain for $50 \%$ dynamic recrystaliization ratio is thought to be useful constituent to characterize Avramitype curve like that a half-life period is a well-known value to compare reaction rate of radioactive isotopes each other, then $t_{0.5}$ which is the time for $50 \%$ recrystallization ratio is utilized as representative criterion to evaluate progress rate of static recrystallization. Consequently eq. (4) is evaluated in this study.

$$
X_{\text {dyn }}=1-\exp \left\{-\ln 2\left(\varepsilon / \varepsilon_{0.5}\right)^{n_{\mathrm{dynx}}}\right\}
$$

where $X_{\text {dyn }}$ is the fraction of dynamic recrystallization, $\varepsilon$ is strain, $\varepsilon_{0.5}$ is the strain for $50 \%$ dynamic recrystallization,

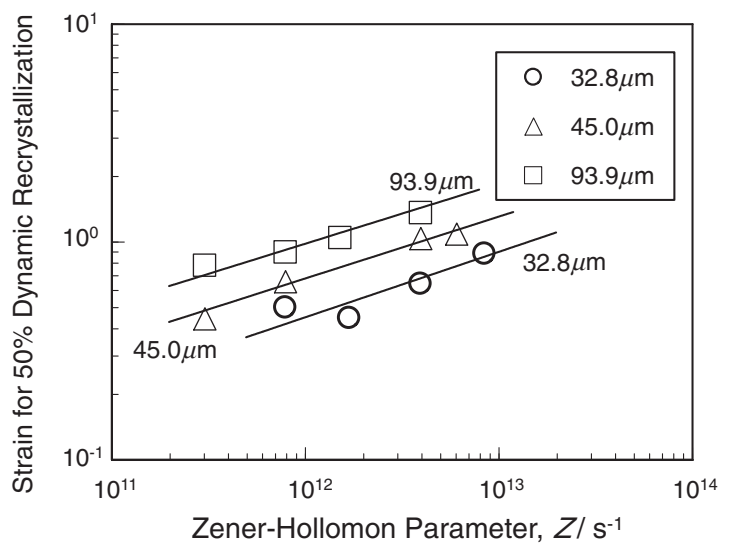

Fig. 12 The relationship between strain for $50 \%$ dynamic recrystallization and Zener-Hollomon parameter.

$n_{\text {dynx }}$ is the constant. $\varepsilon_{0.5}$ is a function of Zener-Hollomon parameter and initial grain diameter.

For several metals, it's reported that $\varepsilon_{0.5}$ depends on various parameters such as initial grain diameter, temperature and strain rate likewise eq. (5). ${ }^{24)}$

$$
\varepsilon_{0.5}=A_{0.5} D_{0}{ }^{m 0.5} Z^{n 0.5}
$$

As shown in Fig. 7, dynamic recrystallization occurred preferably at grain boundary. It indicates the possibility of initial grain diameter dependence in $\varepsilon_{0.5}$ that smaller initial grain diameter gives higher transition rate of dynamic recrystallization because of high density of grain boundary area per unit volume in finer initial grain structure. In fact, such dependence was made sure through the evaluation of transition tendency. Moreover temperature and strain rate dependence of recystallization rate were confirmed. The fraction of dynamic recrystallization is higher as temperature is higher and strain rate is smaller. It's thought that fraction of dynamic recrystallization depends on Zener-Hollomon parameter. The relationship between $\varepsilon_{0.5}$ and Zener-Hollomon parameter is evaluated as shown in Fig. 12. Each $\varepsilon_{0.5}$ is calculated from experimental values across $50 \%$ recrystallization with assuming linear relationship around $50 \%$ region. Data consisted with three kinds of different initial grain diameter are plotted in Fig. 12. Obvious initial grain diameter and Zener-Hollomon parameter dependence of $\varepsilon_{0.5}$ is found. As initial grain diameter is larger and Zener-Hollomon parameter is larger, $\varepsilon_{0.5}$ is larger. Moreover equivalent gradient of approximate 0.3 is confirmed for every initial grain diameter. Calculated value with obtained eq. (5) and experimental data are compared in Fig. 13 in order to confirm the accuracy of approximation. Proportional line of $\varepsilon_{0.5 \text { _cal }}=\varepsilon_{0.5 \text { _obs }}$ and desirable accuracy range of $\pm 10 \%$ compression ratio are added in Fig. 13 for reference. Each plot is within desirable region. Figures 12 and 13 show the appropriateness of eq. (5) for quantitative expression. However it should be pointed that eq. (5) is recognized as brief and mean expression of whole behavior comprehensively. For example, initial grain diameter is contained as one of parameters because dynamic recrystallization occurs preferentially at grain boundary where strain is localized during deformation. Actually prior occurrence of dynamic recystal- 


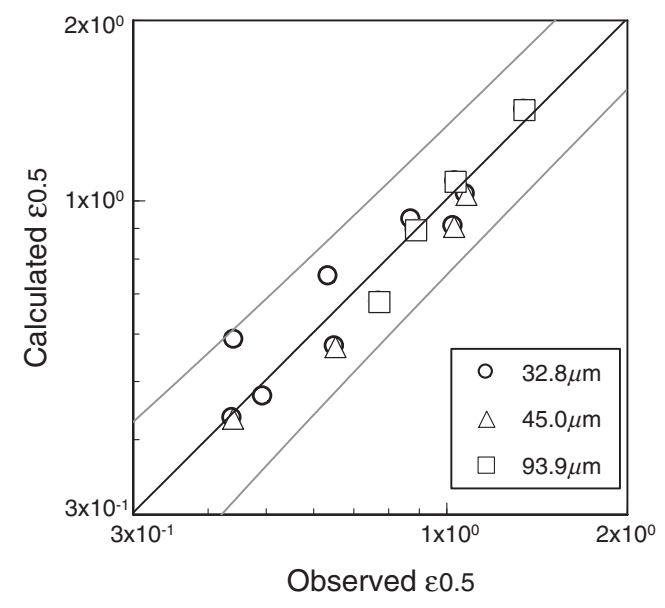

Fig. 13 Comparison of strain for $50 \%$ dynamic recrystallization between calculation and observation.

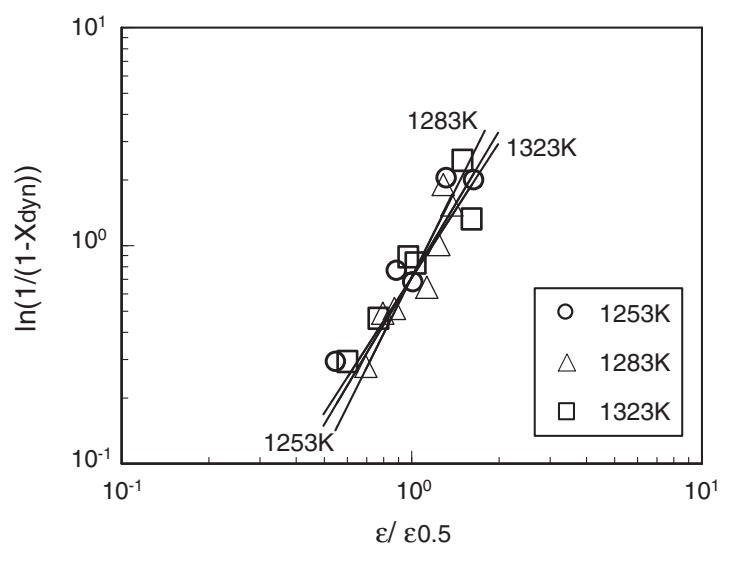

Fig. 14 The relationship between $\ln \left(1 /\left(1-X_{\text {dyn }}\right)\right)$ and $\varepsilon / \varepsilon_{0.5}$. (a)

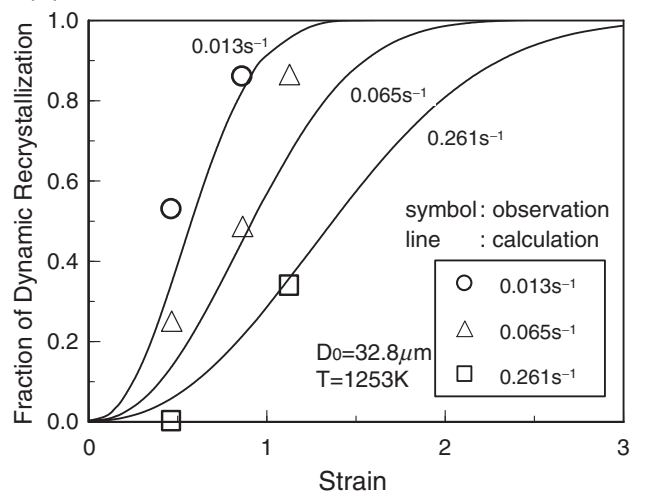

(b)

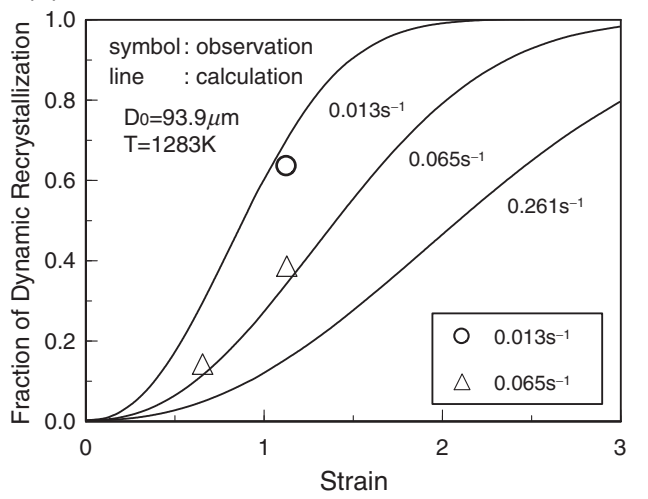

Fig. 15 Observed and calculated transition tendency of $X_{\text {dyn }}$ (a) $D_{0}=32.8 \mu \mathrm{m}, T=1253 \mathrm{~K}$ (b) $D_{0}=93.9 \mu \mathrm{m}, T=1283 \mathrm{~K}$.

lization on initial grain boundary and twin boundary is confirmed in this study. However dynamically recrystallized grain boundary also acts as incubation site of following recrystallization when critical strain is stored locally. Essential contribution of initial grain diameter is changed as recrystallization is progressed.

In Fig. 14, the relationship between $\ln \left\{1 /\left(1-X_{\text {dyn }}\right)\right\}$ and $\varepsilon / \varepsilon_{0.5}$ is evaluated in order to estimate $n_{\text {dynx }}$ in eq. (4) which characterizes transition curve. Data with three kinds of initial grain diameter and different three strain rate are given in Fig. 14 and calculated $\varepsilon_{0.5}$ according to eq. (5) is applied for $\varepsilon_{0.5}$. The temperature dependence of $n_{\mathrm{dynx}}$ is not found obviously and the exponent $n_{\text {dynx }}$ is recognized as constant value of approximate 2.3. Observed and calculated fraction of dynamic recrystallization under different initial grain diameter, temperature and strain rate conditions are summarized as a function of strain in Fig. 15. Each calculated value in Fig. 15 is given by eq. (4) having exponent $n_{\text {dynx }}$ of 2.3 . Obtained approximation brings appropriate prediction curve and is able to trace the actual tendency that the fraction of dynamic recrystallization is influenced by temperature, strain rate, strain and initial grain diameter. The higher the temperature is and the smaller the strain rate is, the higher the fraction of dynamic recrystallization is. Furthermore Fig. 16 shows the comparison between observed and

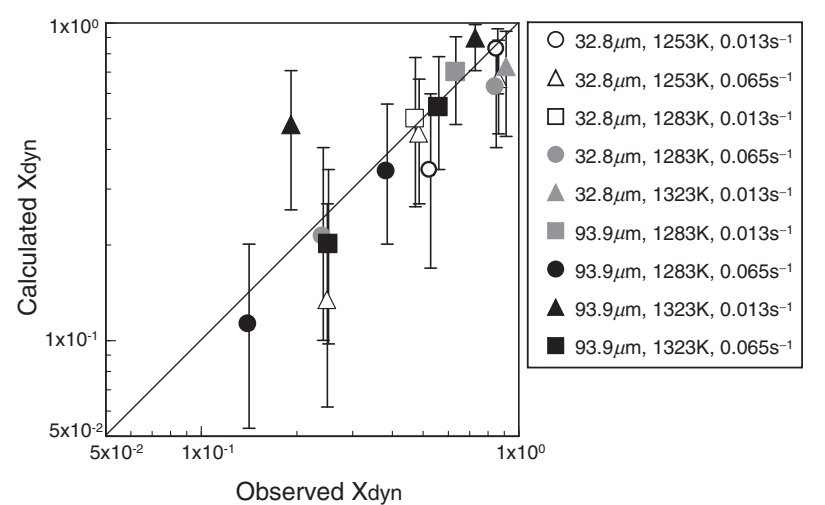

Fig. 16 Comparison of dynamic recrystallization ratio between calculation and observation.

calculated fraction of dynamic recrystallization for various conditions with different initial grain diameter, temperature and strain rate in order to verify the availability of eq. (4). In Fig. 16, each plot is given specific vertical bar that indicates variable range corresponding to $\pm 10 \%$ compression ratio by calculation and $X_{\text {dyn_cal }}=X_{\text {dyn_obs }}$ linear relation is added for reference. Almost all the plots ranging from low to high fraction distribute around $X_{\text {dyn_cal }}=X_{\text {dyn_obs }}$ linear curve such that each scatter bar crosses $X_{\text {dyn_cal }}=X_{\text {dyn_obs }}$ relation. Whole 
transition tendency of dynamic recrystallization ratio is predicted by series of given quantitative equations with suitable accuracy.

Some consideration regarding exponent $n_{\text {dynx }}$ in Fig. 15 is given below. According to Avrami opinion, exponent $n$ from 3 to 4 , from 2 to 3 and from 1 to 2 indicates three, two and one dimensional initiation and growth of static recrystallization respectively. ${ }^{26)}$ Based on this hypothesis, mean value of approximate 2.3 given this study means the dynamic recrystallization proceeds two dimensionally. However it's thought to be difficult to understand the meaning of exponent $n_{\text {dynx }}$ only by Avrami proposal. Under constant temperature and strain rate, grain boundary bulging and initiation of dynamic recrystallization at cross point of grain boundary occurs firstly and dynamically recrystallized grains occupy initial grain boundary as strain increases. Additional strain induces expansion of recystallization region toward interior on initial grains and higher frequency of grain initiation at twin boundary and the area surround carbide-nitride. Moreover sequential recrystallization occurs in the grains already recrystallized. Roberts et al. studied dynamic recrystallization behavior of ferrous alloys, AISI304 and Wnr1.4439 (Fe$18 \mathrm{Cr}-12 \mathrm{Ni}-4.4 \mathrm{Mo}-0.2 \mathrm{~N}$ ) and reported that exponent in Avrami type transition curve has constant value of 1.2 to 1.3 in temperature range from 1273 to $1523 \mathrm{~K}^{27)}$ Furthermore Avrami type transition equation having constant value of 1.5 was derived by theoretical consideration focused on the fact that actual dynamic recrystallization occurred at not only initial grain boundary but also dynamically recrystallized grain boundary and that uneven initiation of dynamic recrystallization on initial grain boundary occurred in dependence on orientation difference with neighboring grains and characterized by application of contributing grain boundary area per unit volume for occurrence of recrystallization as one of parameter. The value of 2.3 given in this study shall be considered as comprehensive and mean exponent characterizing whole transition tendency.

\section{Conclusion}

Isothermal compression tests with various conditions and corresponding microstructure observation of representative $\mathrm{Ni}$ base superalloy, Alloy 718 are carried out in order to reveal the essential and quantitative relationship between deformation and microstructure evolution focused on dynamic recrystallization behavior. And following knowledge contributing numerical calculation is obtained.

(1) The dynamically recrystallized grain diameter depends on temperature, strain rate and is independent of initial grain diameter, strain. And the grain diameter can be expressed as a function of the temperature compensated strain rate, i.e., Zener-Hollomon parameter quantitatively.
(2) Avrami-type equation is available for comprehensive and quantitative expression of dynamic recrystallization transition tendency. And the fraction of dynamic recrystallization is a function of the given strain and the strain for $50 \%$ recrystallization which depends on initial grain diameter and Zener-Hollomon parameter.

\section{REFERENCES}

1) H. L. Eiselstein: ASTM STP 369 (1965) 65-79.

2) E. A. Loria: J O M 40 (1988) 36-41.

3) J. F. Barker, D. D. Krueger and D. R. Chang: Advanced High Temperature Alloys: Processing and Properties, (ASM, 1986) pp. 125137.

4) N. A. Wilkinson: SuperAlloy718, (TMS, 1989) pp. 119-133.

5) T. Matsui, H. Takizawa, H. Kikuchi and S. Wakita: Superalloys2000, (TMS, 2000) pp. 127-133.

6) H. Takizawa, T. Matsui and H. Kikuchi: Simulation of Materials Processing, (Taylor \& Francis, 2001) pp. 601-606.

7) H. Takizawa, T. Matsui and H. Kikuchi: Advanced Technology of Plasticity, (Springer-Verlag, 2002) pp. 673-678.

8) T. Matsui, H. Takizawa and H. Kikuchi: Superalloys2004, (TMS, 2004) pp. 907-915.

9) T. Maki and I. Tamura: J. Soc. Mater. Sci. 30 (1981) 211-217.

10) T. Maki, K. Akasaka, K. Okuno and I. Tamura: Tetsu-to-Hagane 66 (1980) 1659-1668.

11) The Japan Institute of Metals: Metals Data Book, (Maruzen, Tokyo, 1993) p. 23.

12) B. P. Bewlay, V. A. Valitov, O. A. Kaibyshev, Sh. Kh. Mukhtarov, C. U. Hardwicke and M. F. X. Gigliotti: Microstructure Modeling and Prediction during Thermomechanical Processing, (TMS, 2001) pp. $175-185$.

13) R. Srinivasan, V. Ramnarayan, U. Deshpande, V. Jain and I. Weiss: Superalloys 718,625,706 and Various Derivatives, (TMS, 1991) pp. 175-192.

14) N. K. Park, J. T. Yum, Y. S. Na, I. S. Kim, D. H. Kim and S. J. Choe: Superalloys $718,625,706$ and Various Derivatives, (TMS, 1997) pp. $173-182$.

15) C. A. Petri, T. Deragon, F. A. Schweizer and J. J. Schirra: Superalloys 718,625,706 and Various Derivatives, (TMS, 1997) pp. $267-277$.

16) A. A. Guimaraes and J. J. Jonas: Metall. Trans. A 12 (1981) 16551666.

17) C. A. Dandre, S. M. Roberts, R. W. Evans and R. C. Reed: Mater. Sci. Technol. 16 (2000) 14-25.

18) C. I. Garcia, G. D. Wang, D. E. Camus, E. A. Loria and A. J. DeArdo: Superalloys 718,625,706 and Various Derivatives, (TMS, 1994) pp. 293-302.

19) M. J. Weis, M. C. Mataya, S. W. Thompson and D. K. Matlock: Superalloys 718, (TMS, 1989) pp. 135-154.

20) M. S. Lewandowski, V. Sahai, R. C. Wilcox, C. A. Matlock and R. A. Overfelt: Superalloys718,625,706 and Various Derivatives, (TMS, 1994) pp. 345-354.

21) I. Tamura: Tetsu-to-Hagane 74 (1988) 18-35.

22) T. Maki and I. Tamura: Tetsu-to-Hagane 70 (1984) 2073-2080.

23) S. Sakui and T. Sakai: Tetsu-to-Hagane 63 (1977) 285-293.

24) T. Senuma, H. Yada, Y. Matsumura and T. Futamura: Tetsu-to-Hagane 70 (1984) 2112-2119.

25) Y.-S. Na, J.-T. Yeom, N.-K. Park and J.-Y. Lee: J. Mater. Process. Technol. 141 (2003) 337-342.

26) M. Avrami: J. Chem. Phys. 8 (1940) 212-224.

27) W. Roberts, H. Boden and B. Ahlblom: Met. Sci. 13 (1979) 195-205. 